\title{
LETTER
}

\section{Physiological dead space ventilation, disease severity and outcome in ventilated patients with hypoxaemic respiratory failure due to coronavirus disease 2019}

\author{
Francesco Vasques ${ }^{1}$, Barnaby Sanderson ${ }^{1}$, Federico Formenti ${ }^{2,4}$, Manu Shankar-Hari ${ }^{1,3}$ \\ and Luigi Camporota ${ }^{1,2^{*}}$ (i)
}

(C) 2020 Springer-Verlag GmbH Germany, part of Springer Nature

Dear Editor,

The severity of acute hypoxemic respiratory failure (AHRF) in Coronavirus Disease 2019 (COVID-19) correlates correlates poorly with lung weight and lung mechanics, leading to the proposal of phenotypes that may be associated with similar degree of hypoxaemia but different lung volume, weight, and compliance [1]. The alteration of the pulmonary vascular tone and immune thrombosis of the alveolar capillaries [2] may account for these pathophysiological characteristics and for the high physiological dead space observed in these patients.

To describe estimated indices of physiological dead space-and their association with respiratory mechanics, severity of hypoxaemia, biomarkers, and outcomes-we performed a retrospective analysis of adult patients with COVID-19 respiratory failure requiring mechanical ventilation in four medical Intensive Care Units (ICU) within Guy's and St Thomas' NHS Trust-London, UK (Ethics reference: 10,796).

We used the recorded values at the time of worst $\mathrm{PaO}_{2} /$ $\mathrm{FiO}_{2}$ observed on the day of critical care admission. Continuous variables were compared using Mann-Whitney

\footnotetext{
*Correspondence: luigi.camporota@gstt.nhs.uk

1 Department of Adult Critical Care, Guy's and St Thomas' NHS Foundation Trust, King's Health Partners, St Thomas' Hospital, 1st Floor East Wing, Westminster Bridge Road, London SE1 7EH, UK

Full author information is available at the end of the article
}

Luigi Camporota and Manu Shankar-Hari are to be considered joint last (senior) authors.
U test. This cohort included 213 patients (73\% males), mean $(95 \% \mathrm{CI})$ age $56(54-57)$ years, and $\mathrm{PaO}_{2} / \mathrm{FiO}_{2} 128$ (121-135) $\mathrm{mmHg}$. When subdivided in four groups based on cut-off $\mathrm{PaO}_{2} / \mathrm{FiO}_{2}$ of $150 \mathrm{mmHg}$ and compliance of $40 \mathrm{~mL} / \mathrm{cmH}_{2} \mathrm{O} ; 72 \%(n=154)$ had $\mathrm{PaO}_{2} /$ $\mathrm{FiO}_{2}<150 \mathrm{mmHg}$, of these, $112(73 \%$, or $53 \%$ of the overall cohort) had compliance $<40 \mathrm{~mL} / \mathrm{cmH}_{2} \mathrm{O}$ (eTable 1). The mean $(95 \% \mathrm{CI})$ estimated physiological dead space fraction [3] was high in the entire cohort at 0.53 (0.51-0.56).

ICU outcome was available for 193 patients, where estimated physiological dead space fraction was higher in non-survivors [median (IQR), $0.57(0.46-0.65)$ vs. 0.5 $(0.4-0.64) ; p=0.03$ ]. All estimates of physiological dead space increased with the degree of hypoxaemia, but not with the reduction in lung compliance (Fig. 1). Compared with patients with $\mathrm{PaO}_{2} / \mathrm{FiO}_{2}>150 \mathrm{mmHg}$, patients with $\mathrm{PaO}_{2} / \mathrm{FiO}_{2}<150 \mathrm{mmHg}$ had higher estimated physiological dead space fraction $[0.55(0.52-0.57)$ vs. 0.5 $(0.47-0.53) ; p=0.036)($ Fig. 1A), mean $(95 \% \mathrm{CI})$ corrected minute volume [4] [9.3(8.8-9.7) vs. $8.2(7.6-8.8) \mathrm{L} / \mathrm{min}$; $p=0.004$ ] (Fig. 1B), and ventilatory ratio [5] [1.43 (1.37$1.5)$ vs. 1.29 (1.2-1.38); $p=0.001$ ] (Fig. 1C). Although patients with compliance $<40 \mathrm{~mL} / \mathrm{cmH}_{2} \mathrm{O}$ had a higher corrected minute volume [4] [9.4 (8.8-10) vs. 8.8 (8.49.3) $\mathrm{L} / \mathrm{min} ; p=0.023$ ] (Fig. 1C), there was no difference in the two compliance groups in estimated physiological dead space fraction $[0.55(0.48-0.56)$ vs. $0.54(0.52-0.56)$; $p=0.72$ ] (Fig. 1A) and ventilatory ratio [5] 1.4 (1.3-1.5) vs. 1.4 (1.33-1.46); $p=0.76$ ) (Fig. 1B). 


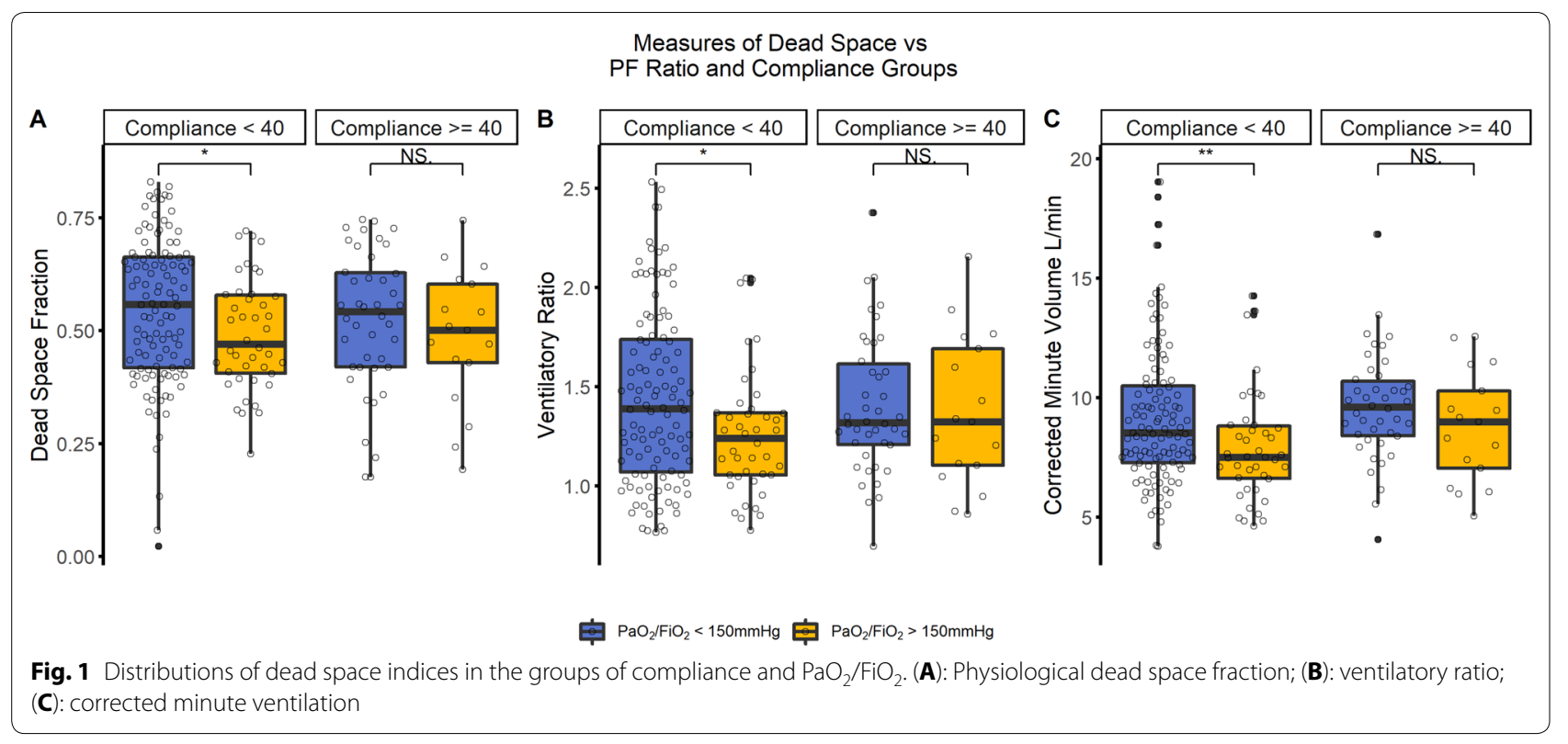

Physiological dead space correlated with hypoxaemia, but it was dissociated from alterations in lung mechanics in COVID-19 ventilated patients. Immunothrombosis is a mechanism that may explain both the increase in physiological dead space and hypoxaemia. Interestingly, we found that the highest median (IQR) levels of D-Dimers [2.1 (1-7) mg/L]; ferritin [1,627 (9142555) ug/L], CRP [219.5 (147.25-324) $\mathrm{mg} / \mathrm{L}]$, and troponin [23 (12-62) ng/L] were seen in patients with $\mathrm{PaO}_{2} /$ $\mathrm{FiO}_{2}<150 \mathrm{mmHg}$, but relatively preserved compliance $\left(>40 \mathrm{~mL} / \mathrm{cmH}_{2} \mathrm{O}\right.$ ). However, these values were statistically similar to the ones recorded in the other groups.

In conclusion, these data suggest that increased physiological dead space is a characteristic of patients with COVID-19 AHRF, with no relation with compliance of the respiratory system. Given that both $\mathrm{PaO}_{2} / \mathrm{FiO}_{2}$ and physiological dead space are worse in non-survivors, it is unclear if dead space is independently associated with mortality or if its effect on outcome is mediated through hypoxaemia.

\section{Electronic supplementary material}

The online version of this article (https://doi.org/10.1007/s00134-020-06197-x) contains supplementary material, which is available to authorized users.

\section{Author details}

'Department of Adult Critical Care, Guy's and St Thomas' NHS Foundation Trust, King's Health Partners, St Thomas' Hospital, 1st Floor East Wing, Westminster Bridge Road, London SE1 7EH, UK. ${ }^{2}$ Centre of Human Applied Physiological Sciences, King's College London, London, UK. ${ }^{3}$ School of Immunology and Microbial Sciences, Kings College London, London SE1 9RT, UK. ${ }^{4}$ Nuffield Department of Clinical Neurosciences, Nuffield Division of Anaesthetics, University of Oxford, Oxford, UK.

\section{Funding}

$\mathrm{S}-\mathrm{H}$ is supported by the National Institute for Health Research Clinician Scientist Award (CS-2016-16-011). FF is supported by the National Institute of Health Research i4i (NIHR200681). The views expressed in this publication are those of the authors and not necessarily those of the NHS, the National Institute for Health Research or the Department of Health and Social Care.

\section{Compliance with ethical standards}

\section{Conflicts of interest}

The authors declare no conflict of interest.

\section{Publisher's Note}

Springer Nature remains neutral with regard to jurisdictional claims in published maps and institutional affiliations.

Accepted: 21 July 2020

Published online: 31 July 2020

\section{References}

1. Gattinoni L, Chiumello D, Caironi P, Busana M, Romitti F, Brazzi L, Camporota $L$ (2020) COVID-19 pneumonia: different respiratory treatments for different phenotypes? Intensive Care Med 46:1099-1102

2. Ackermann M, Verleden SE, Kuehnel M, Haverich A, Welte T, Laenger F, Vanstapel A, Werlein C, Stark H, Tzankov A, Li WW, Li VW, Mentzer SJ, Jonigk D (2020) Pulmonary vascular endothelialitis, thrombosis, and angiogenesis in Covid-19. N Engl J Med 2:19-57

3. Beitler JR, Thompson BT, Matthay MA, Talmor D, Liu KD, Zhuo H, Hayden D, Spragg RG, Malhotra A (2015) Estimating dead-space fraction for secondary analyses of acute respiratory distress syndrome clinical trials. Crit Care Med 43:1026-1035

4. Wexler HR, Lok P (1981) A simple formula for adjusting arterial carbon dioxide tension. Can Anaesth Soc J 28:370-372

5. Sinha P, Fauvel NJ, Singh S, Soni N (2009) Ventilatory ratio: a simple bedside measure of ventilation. $\mathrm{Br} J$ Anaesth 102:692-697 